\title{
Lethal Midline Granuloma-Stewart Nasal Nk/T-Cell Lymphoma-0ur Experience
}

\author{
Cristina Otilia Laza*, Cristian Afternie and Dan Mihail \\ ENT Department, Scju Sf Apostol Andrei Constanta, Romania
}

Submission: March 06, 2018; Published: April 10, 2018

*Corresponding author: Cristina Otilia Laza, ENT Department, Scju Sf Apostol Andrei Constanta, Romania, Email: cristinaotilia@gmail.com

\begin{abstract}
Lethal midline granuloma or Stewart granuloma now recognized as a Naso facial NK/T-cell lymphoma is a rare clinical entity characterized by destruction and mutilation of the naso facial area. It has an unknown etiology, often affect face, nose, para-nasal sinuses, palate, oral cavity and surrounding structures. Because clinical manifestations are often variable and non specific, and the majority of the clinicians are not aware of such a disease this diagnosis is not simple, plus most of the patient are diagnose and treat wrong by a number of doctor loosing time. Plus till the correct diagnosis. Wait for the results of biopsy, IHC, is a long way which lead to a delay in proper treatment the purpose of our article is to present 2 cases of lymphoma TK/NK with in a period of 15 years between them with the difference in possibilities of diagnosis, treatment, etiology, prognosis. Every case was a real challenge I can say a real battle to establish the final diagnosis and to collaborate with someone with experience in the treatment at this horrible disease. Because is very rare (my professor never encounter a patient with destructive midline granuloma in 40 years of work), a lot, s of doctors with different specialities ask for my opinion, because of my "large experience". These require not only clinical feeling but a lot of informations, which means intense study.
\end{abstract}

Keywords: Lethal midline granuloma; Lymphoma; Tk/Nk; Mutilation; Protocol of treatment

\section{Introduction}

Midline destructive lesions of the face were first described in 1897, and later a variety of terms were proposed. Angiocentric lymphoma, malignant granuloma, malignant midline reticulosis, and polymorphic reticulosis. Previously known as lethal midline granuloma or STEWART granuloma, was first introduced in the large category of granulomatous diseases like Wegener, because of the histopathology-chronic inflammatory granulomatous destructive process, but a lots of chronic infections like Tuberculosis, Leprosis, Mucormycosis, and tumors have a similar aspect, but the treatment implicate chimio, radiotherapy after all other possibilities were excluded. This tumor is responsible for the classical destruction of the mid face. In the past, death resulted from inter-current infection of disseminated lymphoma due to a failure of diagnosis or insufficiently. Aggressive oncologic treatment. Recently, similar appearances of aggressive mid facial destruction caused by Cocaine abuse have been reported in which tests for granulomatous diseases and lymphoma have been negative. Todays mid facial necrotizing disease is a naso facial natural killer (NK)/T-cell lymphoma, characterized by granulomatous lesion with destruction of the upper aero digestive tract. Naso facial definitively categorized in the World Health Organization lymphoma classification system as nasal type extra-nodal NK/T-cell lymphoma. It is common in

Asian origin whereas rare in western population. It is difficult to diagnose because of the wide array of similar pathology and nonspecific symptoms. It occurs around the 4 th decade and male to female ratio is $8: 1$ to $2: 1$. Common sites for sinonasal NK/T-cell lymphomas are: nasal cavities the maxillary sinus, nasopharynx, or pharynx, tonsils palate, oral cavity, and hypo pharynx Figure 1.

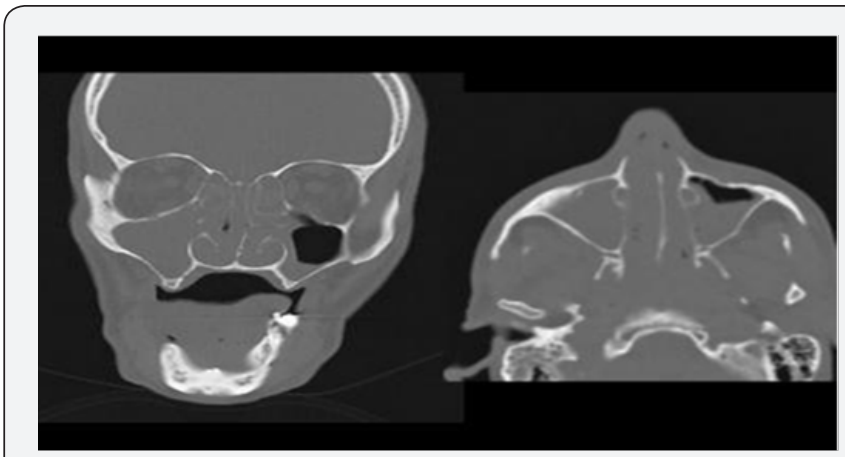

Figure 1: Coronal (left) and axial (right) CT scans of the sinus reveal severe pansinusitis with abnormal nasopharyngeal thickening, right facial edema and right temporal bone pacification. 
Clinical manifestations vary according to the site being affected. The common clinical findings to all such lesions are the progression of an ulceration or vegetative process to destruction of naso facial region, resulting in functional and cosmetic deformity. Natural killer (NK) cell lymphoma is a in an extra nodal non Hodgkin lymphoma most of them (90\%) are of B cell origin. In the past, without immune-hystochemistry it was impossible to describe just using morphologic parameters, without cell markers what type of non Hodgkin lymphoma is Advances in tumor cell biology lead to a better classification of lymphomas (WHO). Controversy still exists if NK-cell lymphoma represents the presence of a true NK cell or merely the presence of a T cell with abnormal cell markers is under debate but identification of more specific cell markers of NK and $\mathrm{T}$ cells will likely resolve this controversy in the future [1-5].

World Health Organization classification of lymphomas

a) Precursor B-lymphoblastic leukemia/lymphoma

b) Chronic lymphocytic leukemia/small lymphocytic lymphoma

c) Lymphoplasmacytic lymphoma

d) Plasma cell myeloma

e) Extraosseous plasmacytoma

f) Extranodal marginal zone B-cell lymphoma of mucosaassociated lymphoid tissue (MALT)

g) Follicular lymphoma

h) Mantle cell lymphoma

i) Diffuse large B-cell lymphoma

j) Intravascular large B-cell lymphoma

B-cell proliferations of uncertain malignant potential include the following:

a) Lymphomatoid granulomatosis

b) Posttransplant lymph proliferative disorder, polymorphic

T-cell and NK-cell neoplasms include the following:

a) Precursor T-lymphoblastic leukemia/lymphoma

b) Blastic NK-cell lymphoma

c) Adult T-cell leukemia/lymphoma

d) Extranodal NKTCL, nasal type

e) Subcutaneous panniculitislike T-cell lymphoma

f) Mycosis fungoides

g) Sézary syndrome h) Primary cutaneous anaplastic large cell lymphoma

i) Peripheral T-cell lymphoma

j) Angioimmunoblastic T-cell lymphoma

k) Anaplastic large-cell lymphoma

T-cell proliferations of uncertain malignant potential include the following:

a) Lymphomatoid papulosis

b) Hodgkin lymphoma

c) Histiocytic and dendritic cell neoplasms

d) Mastocytosis

\section{Pathophysiology}

Extranodal NKTCL outside the lymph nodes manifests in the nasal cavity. Patients with this type tend to have earlier disease (stage I) and is associated with Epstein-Barr virus (EBV), irrespective of the ethnicity of the patient, but the exact mechanism of malignant transformation via EBV is not clear till now. Extranodal nasal type NKTCL demonstrates a predilection for the nasopharynx, palate, skin, soft tissues, orbit, gastrointestinal (GI) tract, and testes. Secondary lymph nodes may be involved in some cases; a disseminated leukemia is even possible. Lymphomas that manifest outside of the nose have a strong association with EBV in Asian patients, but not in whites. The pattern of involvement of the extranasal sites has been hypothesized to be related to the marker CD56-neural cell adhesion molecule. The skin is the most common site of dissemination in Etiology Figure 2.

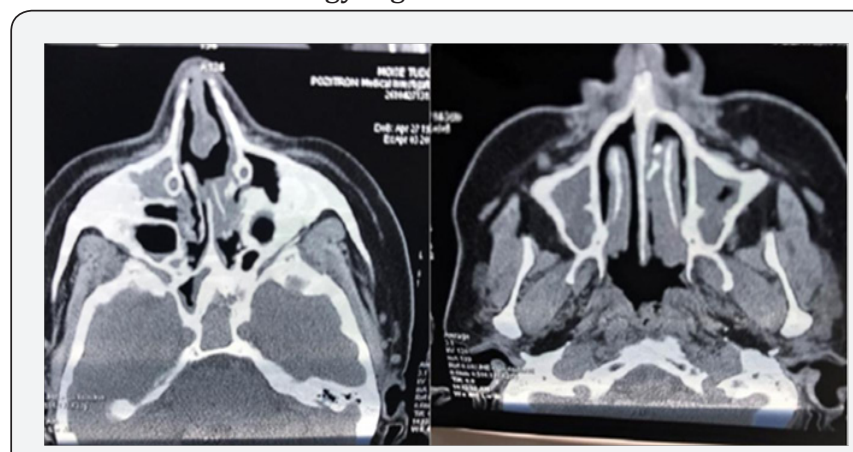

Figure 2: Coronal (left) and axial (right) CT scans of the sinus reveal severe pansinusitis with abnormal nasopharyngeal thickening, right facial edema and right temporal bone pacification.

\section{Risk factors}

a) Inherited immunodeficiencies Klinefelter, Chédiak Higashi, Ataxia Telangiectasia, Wiskott-Aldrich syndrome, and common variable immunodeficiency disease

b) Acquired immunodeficiency diseases Iatrogeniccorticoizi, post-transplant, HIV-1 infection, acquired Hypogammaglobulinemia 
c) Autoimmune disease Sjögreen syndrome, Celiac Sprue, Rheumatoid Arthritis, and Systemic Lupus Erythematosus

d) Chemical or drug exposures Phenytoin, Dioxin, Phenoxyl herbicides, irradiation, and prior chemotherapy or radiotherapy

e) Association with infectious agents EBV, human T-cell leukemia/lymphoma virus-I, and ataxia Telangiectasia syndrome

NK-TC lymphoma is very rare in white populations. In Western populations, the prevalence of nasal lymphomas is estimated at $0.17-1.5 \%$ of all non Hodgkin lymphoma, $45 \%$ of which are thought to be NK-/T-cell in origin. Worldwide is a rare. Disease but it is much more prevalent in Asia, Central and South America. Patients with NKTC-lymphoma commonly present in their sixth decade of life, but the disease has been seen in both geriatric and pediatric populations. Men are more commonly affected with the disease than women, with a male-to-female ratio $3: 1$ [6-10].

\section{Prognosis}

Compared with other subtypes of lymphoma found in the head and neck region, TK-NK lymphoma respond bad at traditional chemo-radiotherapy so the mortality is much higher ,only $6 \%$ of the patients respond complete at the treatment, $45 \%$ survive after 2 years, the rest survive maximum 12,5 month. Presence of a multidrug resistance (P-glycoprotein-positive) phenotype CD56 is thought to facilitate tumor cell dissemination by virtue of its binding properties, and low rates of survival. NKTC lymphoma recurs locally much more frequent (31.4\%) than do either lymphomas presenting in the nasopharynx. The recurrences in the cervical nodes are very low (2.4\%) compared with B-cell lymphomas (14.3\%). Hemophagocytic syndromefever, pancytopenia, hemophagocytic Histiocytic in the bone marrow, and rapid liver function deterioration, are much more common in NKTCLs. EBC virus is consider implicated in etiology so circulating EBV-DNA levels could serve as a valuable biomarker of tumor load for accurate classification of earlystage disease Figure 3.

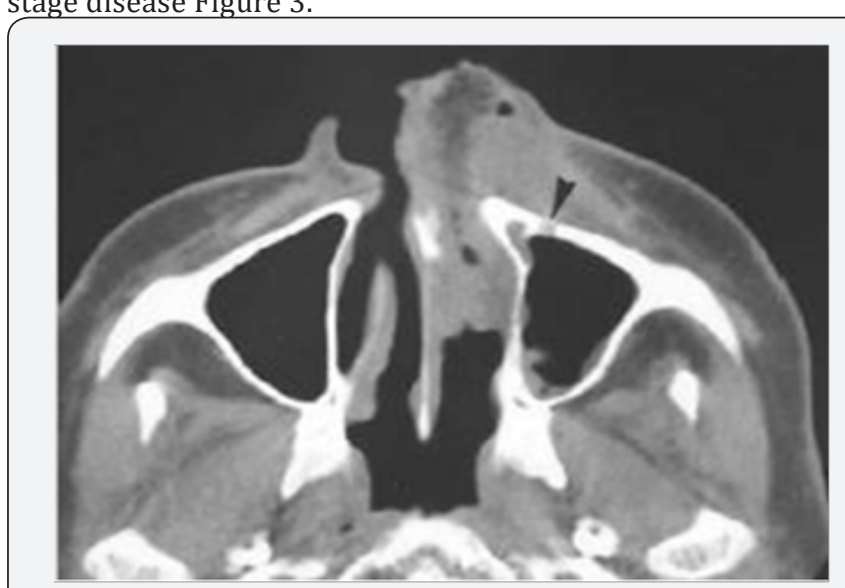

Figure 3: CT scan axial view destructive process of the nasal pyramid with destruction of the nasal septum and turbinates.

\section{History}

General manifestations of natural killer (NK)/T-cell lymphoma (NKTCL) include weight loss, fever, fatigue, night sweats, bone pain. This disorder is associated with aggressive destruction of middle of face. This disease has classically been divided into three stages:

a) Prodromal Stage: Nasal Obstruction and Rhinorrhea. May last few years.

b) Active Stage: Areas of necrosis develop in and around the nasal cavity associated with purulent nasal discharge, crusting and tissue loss. There is also progressive destruction of the nasal framework, palate, upper lip extending in to the pharynx. Orbit and skull base also could be involved.

c) Terminal Stage: This stage is characterized by severe mutilation of the face, exhaustion and eventual death. Systemic metastasis is also seen in this stage. Head and neck manifestations include the following:

Symptoms facial pain and swelling

I. Ocular symptoms

a) Diplopia

b) Decreased visual acuity

c) Orbital swelling

II. Nasosinusal

a) Nasal obstruction

b) Purulent nasal discharge

c) Epistaxis

d) Fetid crusts

e) Cacosmia

f) Anemia

III. Otologic

a) Impaired hearing

b) Otalgia

IV. Oropharyngeal

a) Odynophagia,

b) Dysphasia,

c) Velopharyngeal incompetence

d) Trismus

e) Halitosis

V. Laryngeal

a) Dyspnea 

b) Hoarseness
VI. Pulmonary manifestations
a) Cough
b) Breathing restriction
VII. Gastrointestinal (GI)
a) pain
b) abdominal fullness
c) early satiety
d) perforation
e) hemorrhage
f) Testicular pain may also be reported, as may non healing sores on the skin.

g) Physical Examination

General findings on physical examination include the following:
a) Ulcerations involving the skin
b) Pallor

Head and neck findings include the following:
a) Cranial neuropathies
b) Trigeminal neuralgia
c) VI CN palsy
d) Diplopia
e) Ocular
f) Visual impairment
g) Orbital mass
h) Proptosis
i) Inspection
j) Facial swelling and erythema (midline facial features)
k) Deformation of the nasal pyramid
l) Anterior rhino's copy/posterior rhinos copy
m) Septal perforation
n) Sinusitis
o) Nasal mass Otoscopy
p) Serous otitis media Bucopharyngoscopy
q) Ulcerations of the palate
r) Tonsil
s) Laryngoscopy

t) Ulcerations on the epiglottis

u) Vocal cords Neck

v) Adenopaty

Pulmonary findings include the following:

a) Bronchitis

GI findings include the following:

a) Hepato splenomegaly

b) Abdominal mass

c) A testicular mass

\section{Differential Diagnosis}

Infection (bacterial, fungal, or parasitic), Tuberculosis lupus, Leprosy, Leishmaniosis, Mucormycosis Rhinoscleroma. Inflammatory disease (Sarcoidosis, Wegener granulomatosis, Systemic Lupus Erythematosus, or Polyarteritis nodosa). Neoplastic processes (squamous or bas cell carcinoma, melanoma, esthesio neuroblastoma, adenoid cystic carcinoma, adenocarcinoma, fibrosarcoma, rhabdomyosarcoma, plasma cell myeloma, or an additional sinonasal lymphoma). Cocaine abuse, Trauma (gunshots, bites )with saddle nose deformity, mutilation giant cell granuloma, cholesterol granuloma and lobular capillary hemangioma, Non Hodgkin Lymphomas polymorphic reticulosis Figure 4.

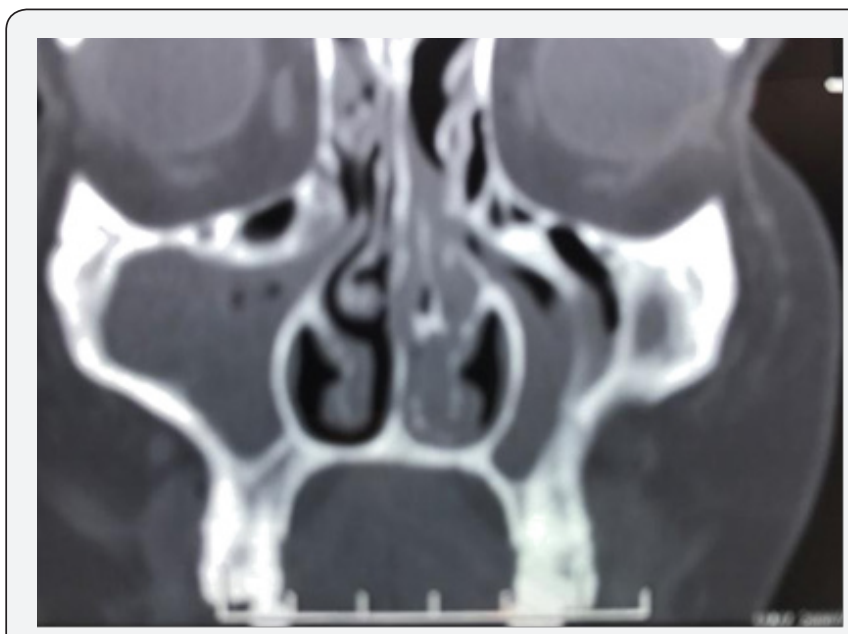

Figure 4: CT scan contrast pansinusitis, fetid purulent discharge necrosis, destruction of the inf turbinate nasal septum.

\section{Laboratory Studies}

a) Test for inflammation PCR, RF

b) Completeblood count(CBC) anemia or lymphocytopenia

c) Liver function tests, Elevated LDH levels have been associated with poorer prognoses

d) Renal function tests

e) Uric acid and calcium levels 
f) Epstein-Barr virus (EBV) titers

g) panca, canca

h) RBW, VDRL

i) IDR ,la PPD, Quanti FERON test, RX thorax

j) Bacteriology, mycology of the nasal discharge to exclude tuberculosis, mycosis

k) rXlung

l) CT scan cranium, neck is important for importance and extent of destructive process

m) CT scan thorax, abdomen-metastasis Magnetic resonance imaging (MRI) of the head is performed in cases of suspected skull base invasion intracranial extension.

\section{Imaging Studies}

a) ENT complete exam

b) Inspection

c) palpation

d) face

e) neck

f) Rhinoscopy ant/posterior

g) rigid endoscopy

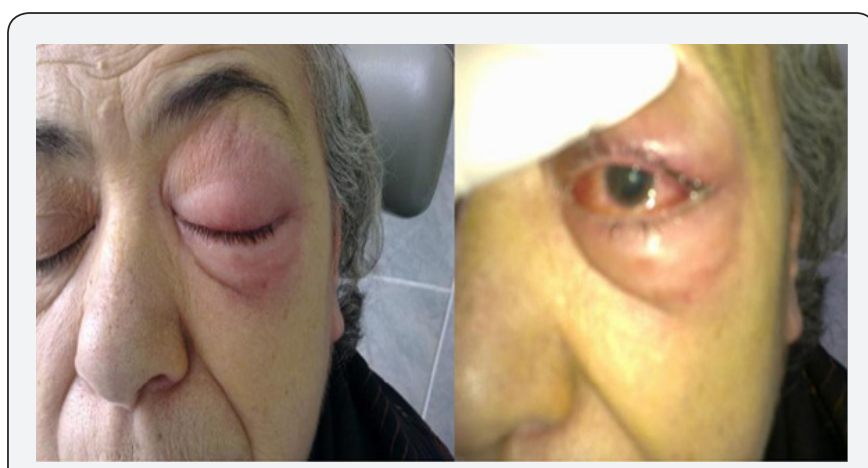

Figure 5: Examination of the face edema, congestion of the left eye both eyelids, edema of the conjunctiva, chemosis , position in the orbit ,mobility normal with the patient consent.

Flexible nasopharyngoscopy with direct laryngoscopy should be performed to characterize the extent of the lesion. Biopsy of the primary site-anatomo-morphology Biopsies showed diffuse infiltrates of pleomorphic large lymphoid cells and atypical small lymphoid cells with frequent mitotic figures, admixed with a large number of inflammatory cells such as granulocytes, macrophages, and plasma cells. Extensive ischemic necrosis was the common characteristic of these lesions. Angiocentric and/or angioinvasive infiltrates were also prominent However, histologic confirmation is indispensable. Angio destruction and necrosis are characteristic for TK-NK lymphoma. It is important to distinguish LMG-NTL from Wegener's granulomatosis which is characterized by necrotizing granulomas and vasculitis, and associated with glomerulonephritis. Antineutrophil cytoplasmic antibodies (c-ANCA) are present in patients with Wegener's granulomatosis, which is useful in diagnosis. Immuno phenotypical tests demonstrate characteristic cell markers for NK-TK lymphoma CD2+, cytoplasmic CD3e+, and CD56+. Other markers are CD7, CD30, CD43, CD45R0, HLA-DR, interleukin (IL)-2 receptor, Lumbar puncture when intrathecal chemotherapy is indicated. Bone marrow aspiration in case of invasion with pancytopenia, hemophagocytic syndrome-fever, hemophagocytic Histiocytic. Genetic tests find EBV in most tumor cells .The virus is present in a clonal episomal form. Various genetic abnormalities have been identified in patients with NKTCLs, but no specific chromosomal translocations Figure 5.

\section{Staging Ann Arbor classification:}

a. Stage I: Involvement in a single lymph node region or single extra lymphatic site

b. Stage II: Involvement of 2 or more lymph node regions on the same side of diaphragm, localized contiguous involvement of only one extra lymphatic site and lymph node region

c. Stage III: Involvement of lymph node regions on both sides of diaphragm; may include spleen

d. Stage IV: Disseminated involvement of one or more extra lymphatic organs with or without lymph node involvement. When added to any of these stage numbers, the letter E denotes extra lymphatic sites, and the letter B indicates the presence of B symptoms (i.e., fever, night sweats, or weight loss).

\section{Treatment}

Because NK/T-cell lymphoma of the head and neck is an extremely rare malignancy, there is not in function a protocol standard for the treatment but should be discuss in a mixed team including planning \with hematologists, oncologists, and radiation oncologists. Currently the most recommended treatment includes CHOP (Cyclophosphamide, doxorubicin, vincristine, prednisone) chemotherapy in conjunction with radiotherapy. The combination of treatments has yielded 5-year survival rates ranging from $20 \%$ to $80 \%$, unfortunately, with a high rate of relapse rate, Also they have a very a high degree of resistance to standard therapy. For these patients, alternative strategies have been investigated with some success. Highdose chemotherapy with or without total-body irradiation, followed by Autologous stem cell rescue, has been used for patients with relapsing disease. More recently, new treatments using the SMILE protocol (dexamethasone, methotrexate, ifosfamide, l-asparaginase, and etoposide) show promising results but adverse effects, including significant myelotoxicity, suggest more research is needed to further develop this promising protocol. Treatment regimen for early stage nasal NKTL that included radiotherapy combined with infusion intraarterial, through the superficial temporal artery, of ifosfamide, 
carboplatin, methotrexate, peplomycin, and etoposide. Surgical management of patients with NKTK-Lymphoma is limited to biopsy, stabilization of the airway if necessary, debunking of disease in case of hemorrhage-ligation of the ECA ,IMA ,cauterization ,laser Reconstruction in case of positive stable response Patients refractory to treatment or with high-risk can benefit from hematopoietic stem cell transplantation. Because of the relatively high mortality, low response rate, and high relapse rate after definitive treatment, patients should be regularly monitored by an otolaryngologist Figure 6 [11-20].

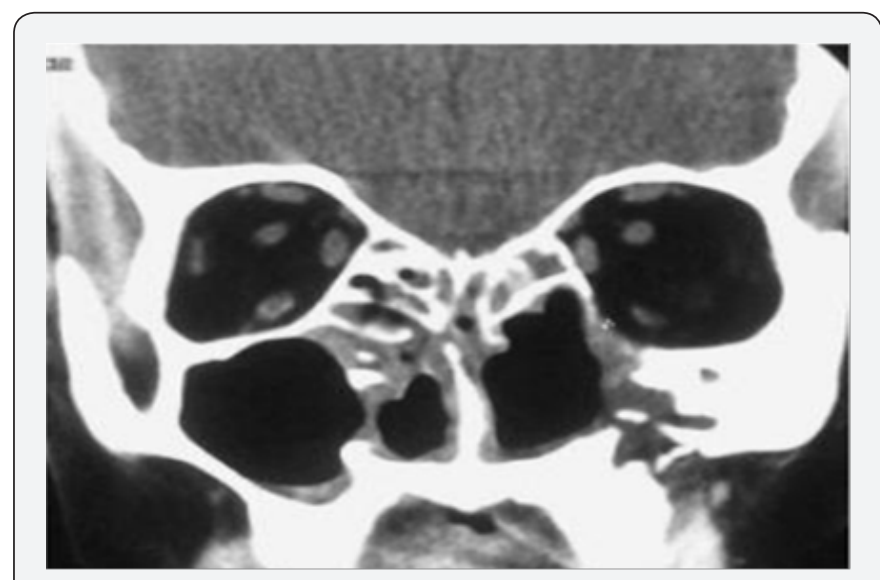

Figure 6: CT scan of paranasal sinus with coronal cut showing destruction of dorsum of nose along with mucosal hypertrophy in maxillary sinus and ethmoidal sinus.

Case Report

In my career I had the chance to diagnose 2 patients with TK/NK lymphoma.

\section{Case $\mathrm{Nr} 1$}

My first patient was a young man, 16 years ago, in a period when Lethal Midline Granuloma was considered a granulomatous disease like Wegener. At the first examination it was a young man 30 years old pale, spreading a fetid smell around him. He accuses nasal obstruction nasal purulent discharge, crusts, epistaxis, and headache, and fever, asthenia, lost in weight. All the symptoms start 7 month before and he describe me all the treatments and surgical procedures suffered anterior. With the nasal pyramid still in place, his face was still symmetric but pain on pressure on both canine fossa and frontal area was severe. On anterior Rhinoscopy on the inferior and lateral walls I saw intense red granulations covered with fetid crusts, a very large ulceration on the nasal septum with complete absence of the cartilage and bone, just superior a rest of bone from perpendicular plate of the ethmoid, green, without mucosa and periosteum. In rest pituitary mucosa presents inflammation, granulations and necrotic areas on the turbinate Thinking that only a very severe, rare disease, can explain such an important destruction, I order direct, exam and cultures for aerobic, anaerobic germs also special mediums of cultures for fungi. Mycobacterium species, tuberculosis, bovis, aviarum, Mycobacterium leprae, Klebsiella rhioscleromatis
In the same time I order cultures for fungi like Aspergillus, Candidiasis, Mucor. Also I run a battery of blood test to appreciate the general status of the patient others for the differential diagnosis, in fact in that time it was an excluding diagnosis with. Wegener granulomatosis=PANCA, CANCA, biopsy histopathology, IHC Tuberculosis-RX thorax, ex BK direct, cultures, Protein chain reaction, Quanti FERON test Tertiary syphilis guma RBW, VDRL, biopsy histopathology, IHC Leprosy biopsy,B. Hansae, cultures Rhinoscleroma Klebsiella rhinos cleromatis, biopsy histopathology ,IHC Cancers biopsy histopathology, IHC Mucormicosis cultures, biopsy histopathology, IHCCT, MRI scans axial, coronal view revealed pansinusitis, necrosis of the intersinuso nasal wall destruction of the inf turbinate perforation of the nasal septum, the extension of the process also endocranial extension. Finally we send the patient on TG .MURES on Oncological Clinic, where my diagnosis was confirm They report the case and it was the single patient with Lethal Midline Granuloma in Europe. They use an aggressive protocol of chemo-radiotherapy but without response. He return without the nasal pyramid, with the hole in his mid face, with high fever, fetid nasal discharge [21-25].

The evolution was negative with fast enlargement of the hole, day by day, starting to involve the orbits than the skull base. The patient accuses excruciated pain-trigeminal neuralgia, headache, vomiting and then starts to bleed from the large hole. At that stage he was extremely aggressive and refuse help, trying to isolate and refusing to eat .In the end he ask for my help so I admit him in our Clinic. First to stop the bleeding I try with sponges like Merocel, Tahocom, than classic with gauzes soaked in an ointment with antibiotic but finally I ligate on that side ECA. Medical treatment consist in MER, plasma, vitamin, sol. glucosis, amino acids, lipids, antialgics, antibiotics but when hemorrhage starts on the other side, he refuse everything, he wants to die at home. Much, more lately, 4 years ago I had the chance to diagnose a 67 year old lady with TK/NK lymphoma in the left maxillary sinus. She was admitted in the clinic for nasal left complete obstruction, purulent nasal discharge severe facial pain including the eye also inflammation, edema of eye lids, fever, night sweets, asthenia. All the accuses starts 4 weeks ago, with progressive aggravation Examination of the face edema, congestion of the left eye both eyelids, edema of the conjunctiva, chemosis, position in the orbit, mobility normal aspect of anterior orbital cellulitis The pain was severe in the canine fossa, suborbital point and in the internal angle of the eye. Clinical aspect was similar with a complicated maxilla ethmoidal chronic suppurated sinusitis with tendencies for complications edema .congestion of the suborbital area with extension in to the orbitanterior cellulitis superficial. There was no lymphadenopathy. There was no history of nasal bleeding, post nasal drip or cough. Routine blood test did not reveal any relevant findings, urine analysis, liver function tests, renal function test were normal except raised ESR and PCR. CT scan studies with the same 
aspect like a fungus ball "extensive sinusitis. The usual lab test were normal so in emergency under general anesthesia- we start with the surgical treatment a combination of FESS and an external procedure for the radical ethmoidectomy type de Lima using a trans maxillary approach type CALDWELLLUC. We send to the lab secretions directly from the sinuses for bacteriology, mycology, BK direct, also the material collected at the anatomopathology the histopathological examination was showing a diffuse Lymphomatoid infiltrates with angiocentric and angiodestructive pattern chronic granulomatous nonspecific inflammations. Extensive area of necrosis with infiltration of plasma cells, histiocytes and eosinophils are present along with atypical lymphocytes [26-30].

Even we use the best antibiotics, antifungal drugs iv, antialgics everyday, we clean and wash out the cavity with saline and a local antibiotics, she complains of more severe pain ,the soft tissues of the face continue to be even more inflamed and a small area of osteitis with a small hole appear in the palatine bone in the sinuses area All other destructive chronic processes were excluded, also no causes for immunosuppressant-posttransplant ,other autoimmune disorders LED ,WG,RP, no DZ, hepatic or renal failure we exclude also a possible Mucormicosis. Because of the palatine hole we ask the opinion of a colleague from oro maxillo facial department, but there were no odontogenic causes our patient use a total prosthesis dentures superior and inferior, gingiva, oral cavity were normal. Serology was positive for EBV IgG antibody but negative for EBV IgM antibody. Human T-lymph tropic virus I/II (HTLV) and HIV antibodies both were negative. Pan CT did not reveal any other involved lymph nodes or organs, bone marrow aspiration was negative for lymphoma involvement or leukemia but showed phagocytosis of nucleated cells by macrophages).

The single way was to ask for a specific immunohistochemistry for TK, NK cells. Possible only in Bucharest. My colleagues from that hospital were very optimistic because they inspect the cavity with an endoscope and were clean and they believe in an OMF examination for them it was necrosis induced by bisphosphonates. In reality our patient never uses in her life such a medication. Finally after long discussions they agreed with the Immunohistochemistry (IHC) study showed abnormal lymphocytes of CD56, CD3.so we finally diagnose an lymphoma TK/NK stage I-EB no lymphadenopathy, no bone marrow, and other organ involvement. The patient was referred immediately to IOB Institute Oncologic Bucharest "Profesor doctor Alexandru Trestioreanu "for further treatment and she was proposed to receive a multidrug chemotherapy of four cycle's protocol (CHOP regimen).followed by external beam irradiation (36Gy). During chemotherapy, her general status continues to deteriorate, because mielotoxicity with neutropenia with spiking fever. She start a complicated treatment that include antibiotics= meropenem and vancomycin, antifungal=fluconazole iv.and an antiviral Vallacyclovire drugs to cov I was very curious about the response to the treatment but unfortunately she died after first session of chemotherapy, because of severe neurotoxin complication [31-35].

\section{Discussion}

i. Nasal NK/T cell lymphomas are aggressive, locally destructive, characterized by a granulomatous necrotic process arising in the nasal cavity or sinuses and extending to the midfacial area with centrifugal destruction of the nasal bone.

ii. It was also called as polymorphic reticulosis, mid line malignant reticulosis, Stewart's granuloma and NK/T-cell lymphoma.

iii. Extranodal NK-T-cell lymphoma accounts for 5-10\% of all non-Hodgkin lymphoma, with most cases reported in East Asia (China, Korea, Hong Kong, and Japan) . The incidence of NK-T-cell lymphoma in the United States is around 0.036 per 10000 people and it has higher prevalence in Hispanic whites and Asian/Pacific Islanders and lowest among blacks. but the EBV infection rate in blacks is very high (92.2\%) which may contribute to the high prevalence of NK/T-cell lymphoma.

iv. The nonspecific clinical symptom is a major obstacle in early diagnosis and management of this lesion.

v. Gross appearance of the lesion is usually looking like necrotic granulomas with ulcerations and destruction of nose and sinuses with destruction of soft tissue, cartilage and bone. There is usually aggressive and lethal progression with rapid destruction of nasofacial area. Nasal septal perforation with mutilation of the surrounding tissues often occurs. The most common symptoms are nasal stuffiness with or without nasal discharge. Ulcerations at nasal cavity or oral cavity along with conjunctivitis may occur.

vi. The diagnosis of mid facial NK/T-cell lymphoma is based on the histopathological picture, immunophenotype of the atypical cells and the analysis of T-cell receptor genes. The surface of the affected site is associated with crusting and necrotic tissue, so the diagnosis of NK/T-cell lymphoma is extremely difficult by taking only punch biopsy, excisional biopsy or deep biopsy is often essential for the diagnosis of this disease. The characteristic histopathological picture in NK/T cell lymphoma shows angiocentric and angiodestructive growth pattern with zonal necrosis. Immunohistochemical study shows positive CD3, CD43, CD45RO, CD20 and CD57 demonstrates the a typical lymphoid cells have T-cell phenotype. Radiological findings in CT scan and MRI are not distinctive for other malignant lesions, typically showing irregular margins, bone destruction and heterogenous contrast enhancement.

vii. Nasal NK/T cell lymphoma is an aggressive lesion with rapid evolution and high mortality if not treated timely. The high mortality is due to septicemia, invasion into blood vessels or into brain leading to abscess formation. 
viii. Treatment of sinonasal NK/T-Cell lymphoma is combined chemotherapy in different protocols ex. CHOP or SMILE in 4-6 courses and radiotherapy The prognosis of this lesion is extremely poor, if it is associated with systemic involvement.

ix. Better prognosis is expected with early and accurate diagnosis along with aggressive treatment with chemotherapy and radiotherapy.

\section{Conclusion}

a. Nasofacial location of NK/T-cell lymphoma is a rarely seen disease.

b. The clinical profile at least in the beginning is nonspecific, that's why the diagnosis is difficult and in a late stage.

c. Diagnosis is based on clinical exam. Imagistics and most important biopsy for histopathology and immunohistochemistry.

d. Early diagnosis and intervention prolongs the survival of the patients.

e. Treatment needs combined chemo and radiotherapy. Surgery is not useful just for biopsy, complication or reconstruction in case of good response.

f. This disease carries a poor prognosis even is localized on the nasofacial area ,is very aggressive with local regional complications or general hematogenous spread.

g. Both cases are impressive but for me were a real fight to sustaine my diagnosis, starting with my ENT colleagues, and ending with oncologist refusing my patient-no one is experienced in such a rare disease.

h. Also to treat such a patient is traumatic, seeing mutilation, pain, depression, suferrence, fighting with complications. My disappointment was higher in the second case -because we manage to obtain the diagnosis very fast, in an early stage, we know more about the diseases, we have protocols of treatment but the final result was dramatic.

\section{References}

1. Proulx GM, Caudra Garcia I, Ferry J, Harris N, Greco WR, et al. (2003) Lymphoma of the nasal cavity and paranasal sinuses: Treatment and outcome of early-stage disease. Am J Clin Oncol 26(1): 6-11.

2. Chan JK, Sin VC, Wong KF, Ng CS, Tsang WY, et al. (1997) Nonnasal lymphoma expressing the natural killer cell marker CD56: A clinic pathologic study of 49 cases of an uncommon aggressive neoplasm. Blood 89(12): 4501-4513.

3. Kim SJ, Jung HA, Chuang SS, Hong H, Guo CC, et al. (2013) Extra nodal natural killer/T-cell lymphoma involving the gastrointestinal tract: Analysis of clinical features and outcomes from the Asia Lymphoma Study Group. J Hematol Oncol 6: 86.

4. Chien CC, Lee HS, Lin MH, Hsieh PP (2016) Primary extra nodal natural killer/T-cell lymphoma of bronchus and lung: A case report and review of literature. Thorac Cancer 7(1): 140-144.
5. Lan SK, Lin CW, Ho HC, Lee MS, Tzeng JE, et al. (2008) Penile metastasis secondary to nasal NK/T-cell lymphoma. Urology 72(5): 1014-1015.

6. Abouyabis AN, Shenoy PJ, Lechowicz MJ, Flowers CR (2008) Incidence and outcomes of the peripheral T-cell lymphoma subtypes in the United States. Leuk Lymphoma 49(11): 2099-2107.

7. Jaffe ES, Chan JK, Su IJ, Frizzera G, Mori S, et al. Report of the workshop on nasal and related extra nodal angiocentric T/natural killer cell lymphomas: Definitions, differential diagnosis, and epidemiology. Am J Surg Pathol 20(1): 103-111.

8. Tlholoe MM, Kotu M, Khammissa RA, Bida M, Lemmer J, et al. (2013) Extra nodal natural killer/T-cell lymphoma, nasal type: Midline lethal granuloma. A case report. Head Face Med 9: 4.

9. Lee J, Suh C, Park YH, Ko YH, Bang SM, et al. (2006) Extra nodal natural killer T-cell lymphoma, nasal-type: A prognostic model from a retrospective multicenter study. J Clin Oncol 24(4): 612-618.

10. Campo E, Swerdlow SH, Harris NL, Pileri S, Stein H, et al. (2011) The 2008 WHO classification of lymphoid neoplasms and beyond: Evolving concepts and practical applications. Blood 117(19): 5019-5032.

11. Ragin C, Edwards R, Heron DE, Kuo J, Wentzel E, et al. (2008) Prevalence of cancer-associated viral infections in healthy afro Caribbean populations: A review of the literature. Cancer Invest 26(9): 936-947.

12. Liang R, Wang Z, Bai Q-X, Gao G-X, Yang L, et al. (2016) Clinical analysis in North-Western China. Oncol Treat 39(1-2): 45-52.

13. Liang R, Wang Z, Bai QX, Gao GX, Yang L, et al. (2016) Natural killer/Tcell lymphoma, nasal type: a retrospective. Oncol Res Treat 39(1-2): 45-52.

14. Jordan MB, Allen CE, Weitzman S, Filipovich AH, McClain KL, et al. (2011) How I treat hemophagocytic lymphohistiocytosis. Blood 118(15): 4041-4052.

15. Han L, Li L, Wu J, Li X, Zhang L, et al. (2014) Clinical features and treatment of natural killer/T-cell lymphoma associated with hemophagocytic syndrome: Comparison with other T-cell lymphoma associated with hemophagocytic syndrome. Leuk Lymphoma 55(9): 204.

16. Filipovich A, McClain K, Grom A (2010) Histiocytic disorders: recent insights into pathophysiology and practical guidelines. Biol Blood Marrow Transplant 16(1): S82-S89.

17. Rivière S, Galicier L, Coppo P, Marzac C, Aumont C, et al. (2014) Reactive hemophagocytic syndrome in adults: A retrospective analysis of 162 patients. Am J Med 127(11): 1118-1125.

18. Kwong YL, Kim WS, Lim ST, Kim SJ, Tang T, et al. (2012) SMILE for natural killer (NK)/T-cell lymphoma: Analysis of safety and efficacy from the Asia Lymphoma Study Group. Blood 120(15): 2973-2980.

19. Ye Xiong Li, Bo Yao, Jing Jin, Wei Hu Wang, Yue Ping Liu et al. (2006) Radiotherapy as primary treatment for stage IE and IIE nasal natural killer/T-cell lymphoma. J Clin Oncol 24(1): 181-189.

20. Kwong Y (2009) High-dose chemotherapy and hematopoietic SCT in the management of natural killer-cell malignancies. Bone Marrow Transplant 44(11): 709-714.

21. Kwong YL (2005) Natural killer-cell malignancies: Diagnosis and treatment. Leukemia 19(12): 2186-2194.

22. Lee J, Au WY, Park MJ, Suzumiya J, Nakamura S, et al. (2008) Autologous hematopoietic stem cell transplantation in extra nodal natural killer/ T-cell lymphoma: A multinational, multicenter, matched controlled study. Biol Blood Marrow Transplant 14(12): 1356-1364.

23. Harris NL, Jaffe ES, Stein H (1999) A revised European American classification of lymphoid neoplasms: a proposal from the International Lymphoma Study Group. Blood 84: 1361-1392. 
24. Harris NL, Jaffe ES, Diebold J (1997) The World Health Organization classification of Neoplastic diseases of the hematopoietic and lymphoid tissues: Report of the Clinical Advisory Committee Meeting, Airlie House, Virginia, Histopathology 36: 69.

25. Jaffe ES, Krenacs L, Kumar S, Kingma DW, Raffeld M (1999) Extra nodal peripheral T-cell and NK-cell neoplasms. Am J Clin Pathol 111 (Suppl. 1): S46-S55.

26. Spits H, Lanier LL, Phillips JH (1995) Development of human T and natural killer cells. Blood 85(10): 2654-2670.

27. Macon WR, Williams ME, Greer JP, Richard D Hamme, Alan D Glick, et al. Natural killer-like T-cell lymphomas: aggressive lymphomas of T-large granular lymphocytes. Blood 87(4): 1474-1483.

28. Kinney MC (1999) The role of morphologic features, phenotype, genotype, and anatomic site in defining extra nodal T-cell or NK-cell neoplasms. Am J Clin Pathol 111(Suppl. 1): S104-S118.

29. Farcet JP, Gaulard P, Marolleau JP, Le Couedic JP, Henni T, et al. (1990) Hepatosplenic T-cell lymphoma: sinusal/sinusoidal localization of malignant cells expressing the T-cell receptor $\gamma \delta$. Blood 75(11): 22132219.
30. Ou CH, Chen CC, Ling JC, Chai JW, Wu CH, et al. (2007) Nasal NK/T-cell Lymphoma: computed tomography and magnetic resonance imaging findings. J Chin Med Assoc 70(5): pp. 207-212.

31. Mallya V, Singh A, Pahwa M (2013) Lethal midline granuloma. Indian Dermatol Online J 4(1): 37-39.

32. Cheung MM, Chan JK, Lau WH, Foo W, Chan PT, et al. (1998) Primary non-Hodgkin's lymphoma of the nose and nasopharynx: clinical features, tumor immunophenotype and treatment outcome in 113 patients. J Clin Oncol 16(1): 70-77.

33. Parker NP, Pearlman AN, Conley DB, Kern RC, Chandra RK (2010) The dilemma of midline destructive lesions: a case series and diagnostic review. Am J Otolaryngol 31(2): 104-109.

34. Mendenhall WM, Olivier KR, Lynch JW Jr, Mendenhall NP (2006) Lethal midline granuloma-nasal natural killer/T cell lymphoma. Am J Clin Oncol 29(2): 202-206.

35. ES Jaffe (1996) Classification of natural killer (NK) cell and NK like T cell malignancies. Blood 87(4): 1207-1210.

Your next submission with Juniper Publishers will reach you the below assets

- Quality Editorial service

- Swift Peer Review

- Reprints availability

- E-prints Service

- Manuscript Podcast for convenient understanding

- Global attainment for your research

- Manuscript accessibility in different formats

( Pdf, E-pub, Full Text, Audio)

- Unceasing customer service

Track the below URL for one-step submission https://juniperpublishers.com/online-submission.php 